PROGRAM ACCREDITATION:

AN ANP MODEL FOR ACCREDITATION CRITERIA PRIORITIZATION

\title{
WITH DEPENDENCIES
}

Mujgan Sagir

ESOGU Engineering Faculty, Eskisehir, Turkey

ABSTRACT

An accreditation provides assurance that a college or university program meets the quality standards of the profession for which that program prepares graduates. The accreditation agencies, in this context, pursue the following objectives in performing the function of "program evaluation and accreditation" set out in its charter, regulations, and directives: Identifying programs that meet minimal evaluation criteria in order to inform society, students, future students, student counselors, parents and legal guardians of students, educational institutions, professional societies, prospective employers, and public organizations; fostering the advancement and continuous improvement of existing programs in engineering as well as the development of new programs; encouraging the development of education in relevant area. This paper presents a revised ANP model in order to modify previous criteria and redefine the dependencies among them. Finally the criteria are prioritized.

\section{Introduction}

MUDEK has a number of criteria for evaluating first cycle (Bachelor) engineering programs.

These criteria aim to ensure the quality of engineering programs at the bachelor level, consisting of a minimum of eight semesters or its equivalent (240 ECTS credits) following secondary education, and to support the continuous improvement of such programs in order to meet the expectations of all constituencies in a dynamic and competitive environment. It is the responsibility of the institution seeking accreditation for an engineering program to demonstrate clearly that the program meets the criteria specified in this document.

There are some basic definitions, key factors for accreditation, such as program educational objectives, program outcomes, assessment and evaluation. Program educational objectives are general statements defining the career goals and professional accomplishments that graduates are expected to achieve in the years following graduation. Program outcomes are statements defining the knowledge, skills, and attitudes that students must have acquired by the time they graduate. Assessment is the process of defining, collecting, and arranging data and evidence through various methods in order to determine the achievement levels of the program educational objectives and program outcomes and evaluation is the process of interpreting the data and evidence obtained from assessments through various methods. The evaluation process should yield the achievement levels of the program educational objectives and program outcomes; it should be used for decisions and actions aimed at improving the program. This paper deals with the prioritization of the criteria considered in this evaluation process. 


\section{Literature Review and Research Design/Methodology}

To do best of our knowledge, there is no paper related to the accreditation criteria and their prioritization. There are papers related to the accreditation, such as Anwar and Richards (2018). They compare the ABET and EC accreditation criteria. Omar, M.A. and Ismail, M.A. (2018) analyzed engineering higher education courses in terms of direct assessment. There are many papers related to the accreditation of a specific institute and they are mostly related to health issues such as Zima, T. (2017). In this paper, accreditation of medical laboratories is analyzed and benefits for labs are discussed.

The MUDEK main criteria are Students, Program Educational Objectives, Program Outcomes, Continuous Improvement, Curriculum, Faculty Members, Facilities, Institutional Support and Financial Resources, Organization and Decision-Making Processes and Discipline-Specific Criteria. In the current process, a program is evaluated in terms of each specific criteria and a program that meets the minimum requirements for each criterion is accredited. The programs are independent from each other so there is no ranking among them. On the other hand, we believe that it is good to know the degree of accreditation if such a system or mechanism can be proposed to do that and therefore a program may have a chance to improve themselves with respect to that criterion although it meets minimum requirements for that. For this purpose, we need to prioritize the criteria first and then to evaluate a program with respect to each criterion not by just saying that the minimum requirements are hold but also on which degree.

\section{Data/Model Analysis}

Since the criteria are dependent to each other, we develop an Analytic Network Process model to prioritize the criteria. Our model is a main model just to evaluate the criteria of the process, there is no alternative for the moment, but this template can easily be used to rank some programs under consideration. Figure 1 presents the ANP model for main criteria of Engineering Accreditation process. A screen view is provided, as an example, when the "Method for PEO (program educational objectives) Definition" criterion is selected. The red bordered criteria are the ones that given criterion is affected by each of them. 


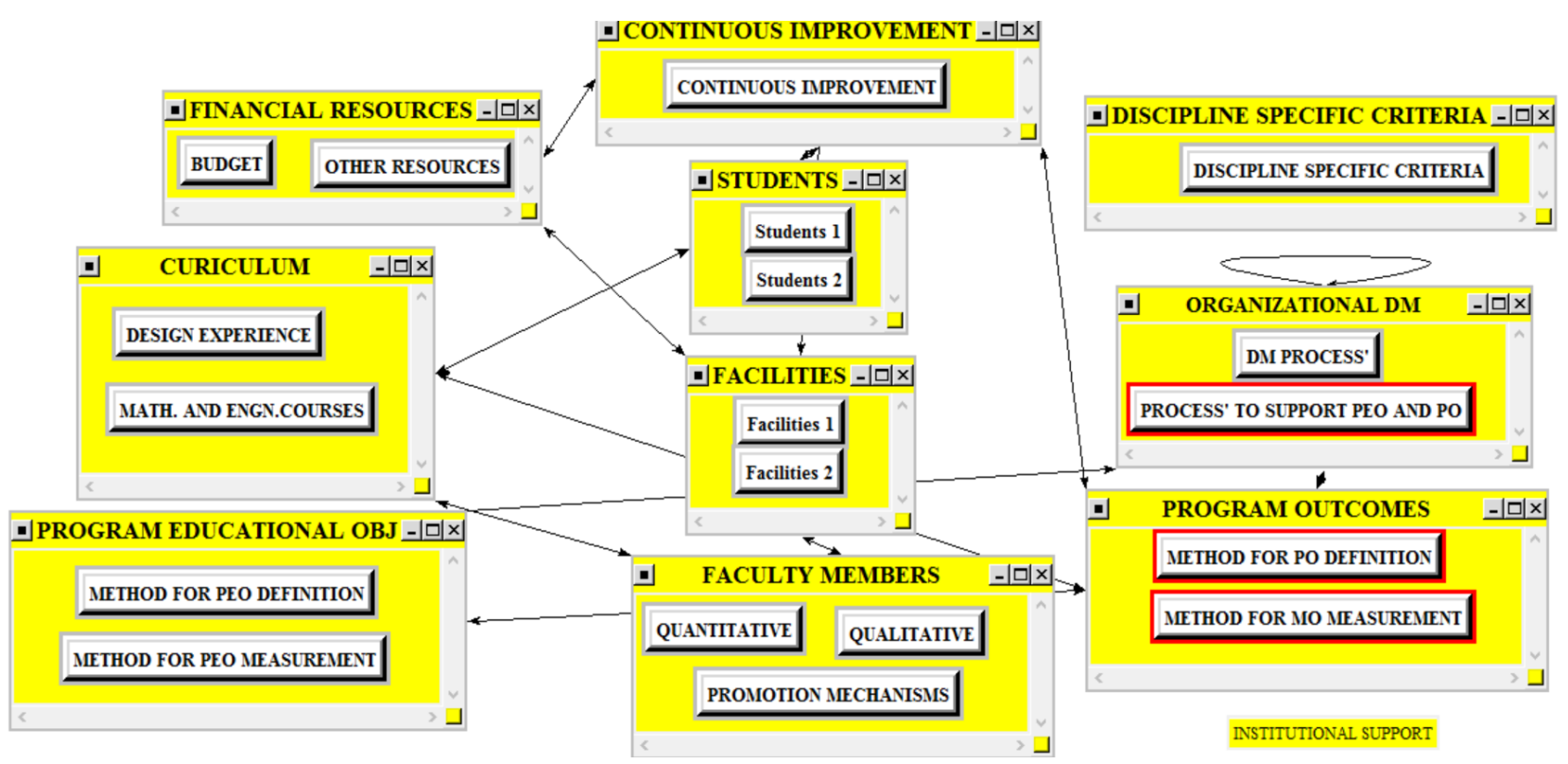

Figure 1. A screen view of main ANP network

Once a model is developed, by defining the relations among the criteria, required number of paired comparisons is performed. This gives us the priorities for not only the clusters but also the elements in each of them.

\section{Conclusion and Limitations}

Each main criterion has a number of subcriteria as shown in Figure 1. We obtain the priorities of the main criteria as seen in Table 1. Due to the space limitations, we do not include all related criteria with their priorities.

Table 1. Criteria priorities

\begin{tabular}{|l|c|l|c|}
\hline Criteria & Weight & Criteria & Weight \\
\hline Students & 0,12 & Faculty Members & 0,08 \\
\hline $\begin{array}{l}\text { Program Educational } \\
\text { Objectives }\end{array}$ & 0,14 & Facilities & 0,09 \\
\hline Program Outcomes & 0,11 & $\begin{array}{l}\text { Institutional Support and } \\
\text { Financial Resources }\end{array}$ & 0,14 \\
\hline $\begin{array}{l}\text { Continuous } \\
\text { Improvement }\end{array}$ & 0,10 & $\begin{array}{l}\text { Organization and Decision- } \\
\text { Making Processes }\end{array}$ & 0,12 \\
\hline Curriculum & 0,10 & & \\
\hline
\end{tabular}

As noted before, by using an ANP model, we are able to prioritize the criteria of an accreditation process. This type of structure gives institutions a chance to improve their curricula, program educational objectives and/or learning outcomes by analyzing dependencies among criteria. Therefore a decision maker can figure out required actions by observing strong and weak characteristics of the system. 
This is a simple model, needs to be improved, on the other hand, can be a good motivation point for further analysis. Besides, we do not include a set of alternatives here, but the model can be used to compare different educational programs by considering them as alternatives.

\section{Key References}

Anwar, A.A.; Richards, D.J. (2018), Comparison of EC and ABET Criteria. Journal of Professional Issues in Engineering Education and Practice, 144, 3, 06018001.

Omar, M.A., İsmail, M.A. (2018), Advanced application for direct assessment of course and program learning outcomes in engineering higher education, International Journal of Advanced and Applied Sciences, 5,3,46-52.

Zima, T. (2017). Accreditation of medical laboratories-system process, benefits for labs., Journal of Medical Biochemistry, 36,3,231-237. 